\title{
Polymerization of ethylene oxide using yttrium isopropoxide
}

\author{
Young K. Choi ${ }^{\text {a) }}$, Willem M. Stevels, Marc J. K. Ankoné, Pieter J. Dijkstra, \\ Sung W. Kim ${ }^{\text {a) }}$, Jan Feijen* \\ Department of Chemical Technology and Institute of Biomedical Technology, University \\ of Twente, P.O. Box 217, 7500 AE Enschede, The Netherlands
}

(Received: May 2, 1996; revised manuscript of June 4, 1996)

\section{SUMMARY:}

Well defined poly(ethylene oxide)s were prepared using yttrium isopropoxide as an initiator. End group analysis using ${ }^{1} \mathrm{H}$ - and ${ }^{13} \mathrm{C}$ NMR spectroscopy revealed that only polymers with isopropyl ether and hydroxyl end groups were produced. The molecular weight is controlled by the initial amount of initiator added and low polydispersity poly$\operatorname{mer}\left(\bar{M}_{\mathrm{w}} / \bar{M}_{\mathrm{n}} \approx 1.1\right)$ was isolated. Sequential polymerization indicated the suitability of this initiator for macromolecular engineering.

\section{Introduction}

Living ring-opening polymerization of ethylene oxide can be conveniently carried out using alkali metal anionic initiators ${ }^{1)}$. Metal alkoxides are the active species in these polymerizations. Due to transfer reactions, polymerization of substituted oxiranes with these highly basic initiators is more difficult to control. Other metal alkoxides, such as aluminium isopropoxide can also be used for the polymerization of ethylene oxide ${ }^{2)}$. However, addition of a Lewis acid is necessary to achieve reasonable polymerization rates and conversion. The zinc chloride used for this purpose plays a role in the initiation itself as evidenced by the presence of chloride terminated polymer ${ }^{3}$. These mixed metal systems are not suitable for the preparation of well-defined poly(ethylene oxide)s. Well defined polymers can be prepared by using homogeneous aluminium- and zinc porphyrins ${ }^{4,5)}$. When using the zinc compound, continuous irradiation with a high-power light source was necessary to achieve reasonable rates and conversion.

In pseudo anionic ring-opening polymerization of lactones it was shown that lanthanide metal alkoxides are valuable alternatives to aluminium alkoxides, providing increased polymerization rates without broadening of molecular weight distribution $^{6,7)}$. Furthermore these lanthanide alkoxide initiators were successfully applied in the synthesis of several new macromolecular architectures. No examples of ringopening polymerization of ethylene oxide by homogeneous lanthanide alkoxides are currently available. In this paper the use of commercially available $\mathrm{Y}_{5}(\mathrm{O})\left(\mathrm{O}^{\mathrm{i}} \mathrm{Pr}\right)_{13}$, yttrium isopropoxide, in ethylene oxide polymerization is discussed.

a) Center for Controlled Chemical Delivery, University of Utah, Salt Lake City, Utah 84108 , USA. 


\section{Experimental part}

\section{General}

Yttrium isopropoxide $\left(\mathrm{Y}_{5}(\mu-\mathrm{O})(\mathrm{OiPr})_{13}\right)$ was purified as previously described and kept in a glove box ${ }^{8)}$. Ethylene oxide (Fluka; 99.8\%) was used as received. Methylene chloride was carefully distilled under nitrogen from calcium hydride. All glassware was carefully dried before use and all manipulations were carried out in a glove box or using Schlenk type glassware under argon.

\section{Polymerization}

In a typical polymerization, a pre-determined amount of yttrium isopropoxide, dissolved in methylene chloride, was syringed into a thick-walled $(3 \mathrm{~mm})$ glass reaction bottle specially designed for pressure experiments, and closed with Teflon Young valves. The reaction bottle was connected to a vacuum line and subjected to a high vacuum (0.005 Torr) to remove all dichloromethane. The reaction bottle, cooled with a liquid nitrogen bath, was charged with the required amount of ethylene oxide by a trap-to-trap distillation method and then immersed in an oil bath $\left(80^{\circ} \mathrm{C}\right)$ for a predetermined time. The reaction mixture was heterogeneous at the beginning of the polymerization and became homogeneous as the polymerization proceeded. The product was isolated after dissolving the mixture in methylene chloride, followed by a terminating reaction with an excess amount of water relative to initiator and removal of all volatiles.

\section{Measurements}

${ }^{1} \mathrm{H}$ - and ${ }^{13} \mathrm{C}$ NMR spectra of samples dissolved in $\mathrm{CDCl}_{3}$ were recorded using a Bruker AS 250 FT spectrometer. Gel permeation chromatography (GPC) was used to determine molecular weights and molecular weight distributions. A Waters $6000 \mathrm{~A}$ GPC apparatus equipped with four $\mu$ Styragel (Waters) columns $\left(500,10^{3}, 10^{4}\right.$, and $10^{5} \AA$ pore diameter) was used, combined with a $\mathrm{H} 502$ viscometer detector (Viscotec Corp.) for determination of molecular weights after calibration with polystyrene standards. The samples dissolved in chloroform $(0.7-1.0 \mathrm{w} / \mathrm{v} \%)$ were injected at $25^{\circ} \mathrm{C}$ with chloroform as the eluent at a flow rate of $2.5 \mathrm{~mL} / \mathrm{min}$.

\section{Results and discussion}

In preliminary experiments the conversion of ethylene oxide by ring-opening polymerization using yttrium isopropoxide as an initiator was investigated. Polymerization proceeded very slowly at ambient temperatures and therefore further experiments were performed at elevated temperatures. Polymerization reactions were carried out in bulk at $80^{\circ} \mathrm{C}$ and at an initial monomer to initiator ratio of approximately $[\mathrm{M}]_{0} /\left[\mathrm{I}_{0}=200\right.$ (Tab. 1, entries $1-4$ ). In Fig. 1 the time-conversion relationship of the ethylene oxide polymerization is presented. Under these conditions the ethylene oxide monomer was completely consumed in about $80 \mathrm{~h}$. The polymers isolated after quenching the reaction mixture with water were characterized by their proton and carbon NMR spectra.

In Fig. 2 a the ${ }^{1} \mathrm{H}$ NMR spectrum of the poly(ethylene oxide) (PEO) obtained after $80 \mathrm{~h}$ reaction time is presented. The signals at $\delta=1.09$ and $3.58 \mathrm{ppm}$ are attributed to the methyl protons of the terminal isopropyl ether and the methylene protons of 
Tab. 1. Bulk polymerization of ethylene oxide with yttrium isopropoxide at $80^{\circ} \mathrm{C}$

\begin{tabular}{|c|c|c|c|c|c|c|c|}
\hline \multirow{2}{*}{\multicolumn{2}{|c|}{ No. $[\mathrm{M}]_{0} /[\mathrm{I}]_{0}$}} & \multirow{2}{*}{$\begin{array}{l}\text { Reaction } \\
\text { time in } h\end{array}$} & \multirow{2}{*}{$\begin{array}{l}\text { Conversion } \\
\text { in } \%\end{array}$} & \multirow{2}{*}{$\frac{\bar{M}_{\mathrm{n}, \mathrm{cal}} \cdot 10^{-3}}{\mathrm{~g} / \mathrm{mol}}$} & \multirow{2}{*}{$\frac{\bar{M}_{\mathrm{n}, \mathrm{NMR}} \cdot 10^{-3}}{\mathrm{~g} / \mathrm{mol}}$} & \multirow{2}{*}{$\frac{\bar{M}_{\mathrm{n}, \mathrm{GPC}} \cdot 10^{-3}}{\mathrm{~g} / \mathrm{mol}}$} & \multirow{2}{*}{$\bar{M}_{\mathrm{w}} / \bar{M}_{\mathrm{n}}$} \\
\hline & & & & & & & \\
\hline 1 & 205 & 18 & 29 & 1.0 & 1.0 & 0.6 & 1.12 \\
\hline 2 & 185 & 24 & 41 & 1.3 & 1.4 & 0.8 & 1.12 \\
\hline 3 & 200 & 43 & 63 & 2.1 & 2.1 & 1.4 & 1.12 \\
\hline 4 & 205 & 48 & 71 & 2.4 & 2.3 & 1.9 & 1.11 \\
\hline 5 & 257 & 85 & 100 & 4.3 & 4.6 & 3.8 & 1.11 \\
\hline 6 & 153 & 48 & 100 & 2.6 & 2.5 & 1.8 & 1.10 \\
\hline 7 & 110 & 48 & 100 & 1.9 & 2.0 & 1.3 & 1.07 \\
\hline 8 & 55 & 24 & 100 & 0.9 & 0.9 & 0.5 & 1.05 \\
\hline
\end{tabular}

Fig. 1. Conversion as a function of time for the yttrium isopropoxide initiated polymerization of ethylene oxide at $80^{\circ} \mathrm{C}$ $\left([\mathrm{M}]_{0} /[\mathrm{I}]_{0}=200\right)$

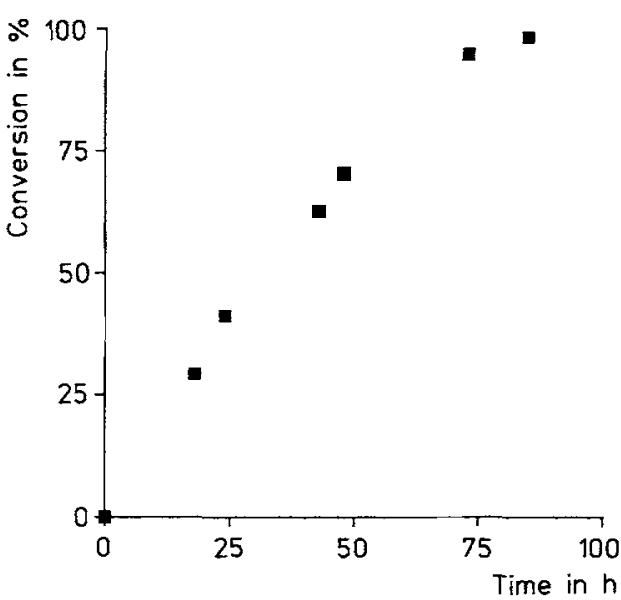

the oxyethylene unit of PEO, respectively. In order to identify the hydroxyl functional end group, which chemical shift coincides with the backbone signal of PEO as does the terminal methine group, a ${ }^{1} \mathrm{H}$ NMR spectrum was recorded after reacting the polymer with trifluoroacetic anhydride. The formation of the trifluoroacetic ester renders the neighbouring methylene protons as a triplet at $\delta=4.4 \mathrm{ppm}$, which is well separated from the large PEO backbone signal as shown in Fig. $2 \mathrm{~b}$. The relative intensity of the methyl protons $\left(\mathrm{CH}\left(\mathrm{CH}_{3}\right)_{2}\right)$ to the methylene protons $\left(-\mathrm{CH}_{2}-\right)$ next to trifluoroacetic ester was determined to be 3.06. A PEO hydroxyl end group can also be observed directly by recording a spectrum in dimethyl sulfoxide- $d_{6}{ }^{9,10)}$ and this is shown in Fig. $2 \mathrm{c}$ ( $\mathrm{OH}$ at $\delta=4.5 \mathrm{ppm}$ ). These results show that the PEO is end-capped with an isopropoxy and hydroxyl group. The integral ratios of the signals in the ${ }^{1} \mathrm{H}$ NMR spectra allow the calculation of the number average molecular weight of the polymer. The values determined agreed well with the values calculated on the basis of monomer to initiator used. The values determined by gel-permeation 


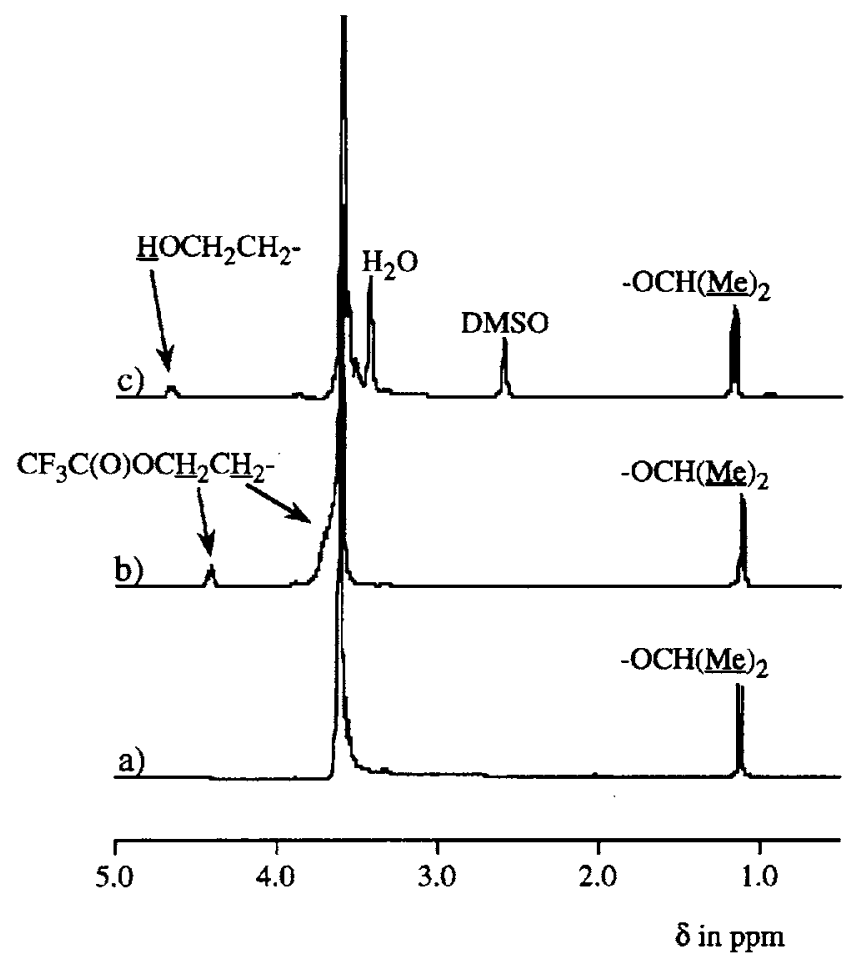

Fig. 2. ${ }^{1} \mathrm{H}$ NMR spectra of poly(ethylene oxide) prepared by polymerizing ethylene oxide using yttrium isopropoxide in bulk at $80^{\circ} \mathrm{C}$ : (a) in chloroform- $d_{1}$, (b) in chloroform- $d_{1}$ with addition of excess trifluoroacetic anhydride, (c) in dimethyl sulfoxide- $d_{6}$

chromatography (GPC) measurements (Tab. 1) were measured relative to polystyrene standards and in all cases are somewhat lower than those determined from the ${ }^{1} \mathrm{H}$ NMR spectra.

The ${ }^{13} \mathrm{C}$ NMR spectra of the prepared PEO's show distinct signals for the backbone methylene carbon atoms at $\delta=70.5 \mathrm{ppm}$ and the $\alpha$ - and $\beta$-carbon atoms of the $\mathrm{CH}_{2} \mathrm{CH}_{2} \mathrm{OH}$ end group at $\delta=62.0$ and $\delta 72.5 \mathrm{ppm}$, respectively. The $\alpha$-carbon is shifted downfield upon derivatization of the hydroxyl end group into its trifluoroacetic ester (Fig. 3). Contrary the $\boldsymbol{\beta}$-carbon atom is shifted upfield upon derivatization. Similar chemical shifts were observed in the ${ }^{13} \mathrm{C}$ NMR spectra of commercially available PEO containing only hydroxyl end groups. The signals of the methine carbon atom of the terminal isopropyl ether and the $\alpha$ methylene carbon atom of the neighbouring oxyethylene unit were found at $\delta=72.0$ and $67.5 \mathrm{ppm}$, respectively. In all spectra separate signals around the signal of the polymer backbone can be discerned. These could not be assigned unequivocally on basis of the experiments performed.

From the results presented above it is proposed that the yttrium-isopropoxy oxygen bond is the active site in the ethylene oxide polymerization, which is similar as 


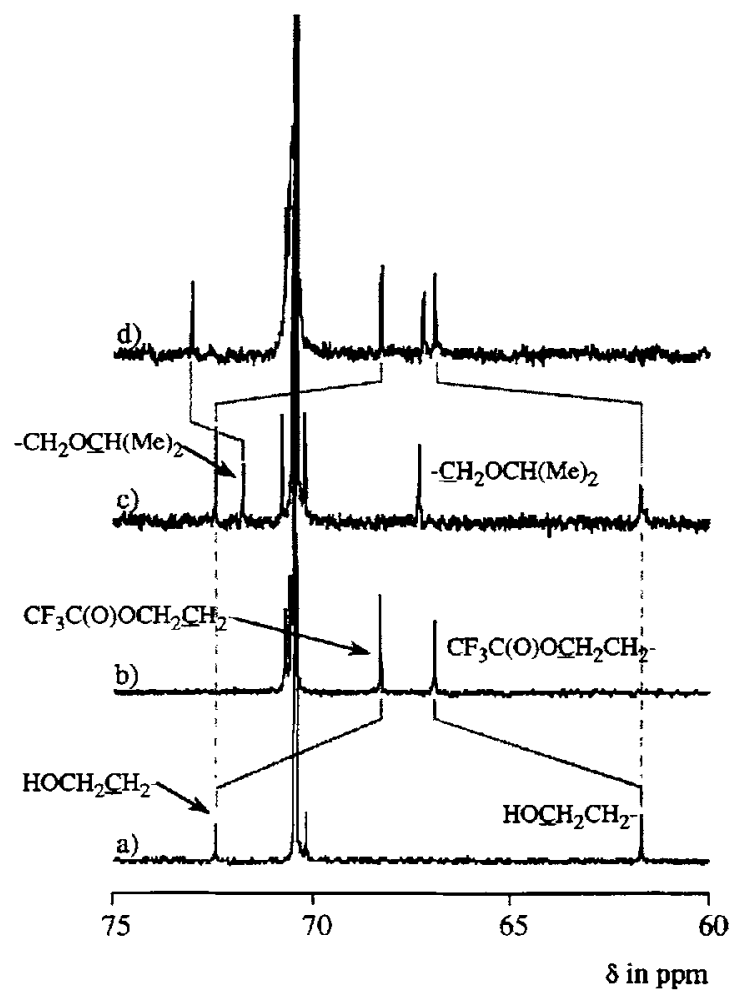

Fig. 3. Details of the ${ }^{13} \mathrm{C}$ NMR spectra in chloroform- $d_{1}$ of $(a)$ a commercial dihydroxyl functionalized poly(ethylene glycol); (b) same as (a), with addition of excess trifluoroacetic anhydride; (c) poly(ethylene oxide) prepared by polymerizing ethylene oxide using yttrium isopropoxide in bulk at $80^{\circ} \mathrm{C}$; (d) same as (c), with addition of trifluoroacetic anhydride. The signals connected by gray lines belong to the protons before and after conversion of the hydroxyl end groups into their corresponding trifluoroacetic esters

\section{Scheme 1:}

Proposed mechonism for the polymerization of ethylene oxide by yttrium isopropoxide

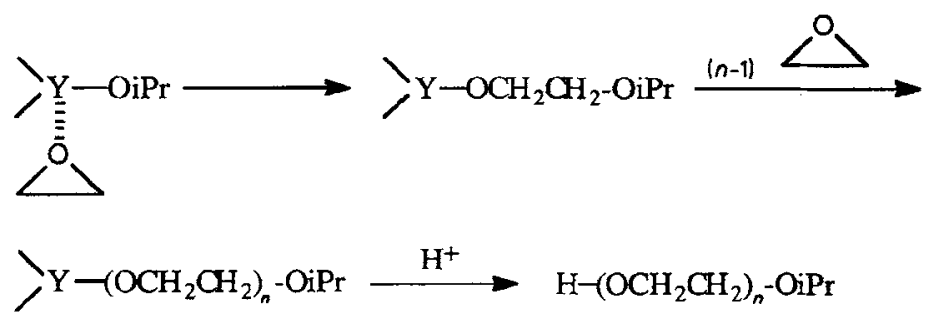


reported for the polymerization of lactide and $\varepsilon$-caprolactone ${ }^{8)}$. Propagation might proceed through the continuous insertion of monomers into the $\mathrm{Y}-\mathrm{OR}$ bond (Scheme 1).

Polymerizations were carried out at various monomer to initiator ratios (Tab. 1 , entries 5-8). In Fig. 4 the degree of polymerization as a function of monomer to

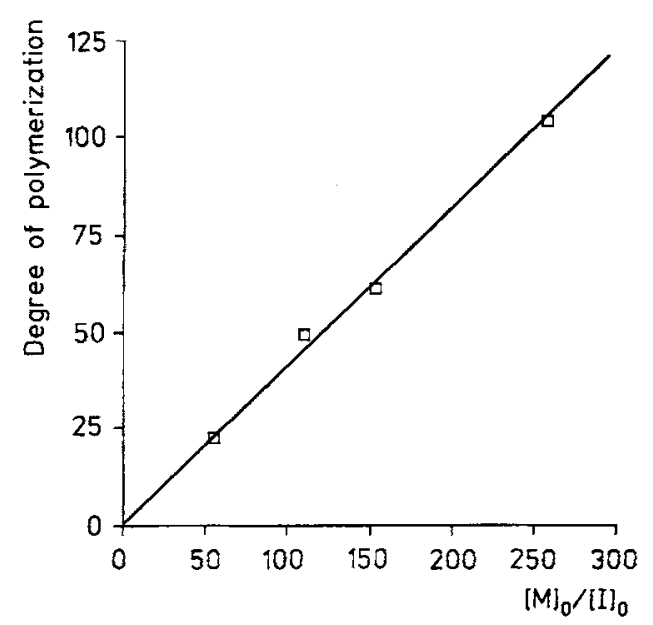

Fig. 4. Degree of polymerization as determined by ${ }^{1} \mathrm{H}$ NMR end group analysis as a function of the initial monomer to initiator ratio for the polymerization of ethylene oxide using yttrium isopropoxide

initiator ratio is presented. The degree of polymerization was determined by calculation of the normalized ratio of the PEO backbone integral to the integral of the terminal isopropyl group in the ${ }^{1} \mathrm{H}$ NMR spectrum. The degree of polymerization is linearly proportional to the monomer to initiator ratio. The slope as determined by a linear regression is 0.41 . The reciprocal value of the slope $(1 / 0.41=2.5)$ gives the number of active sites, which is well consistent with the number of isopropoxy groups per yttrium molecule $(13 / 5=2.6)$ in the initiator. This result shows that all isopropoxy groups in the initiator were involved in the ethylene oxide polymerization.

Sequential polymerization of ethylene oxide was conducted in order to probe the living character of the propagating end. First, bulk polymerization of ethylene oxide was carried out to almost complete conversion. The polymerization mixture was dissolved in methylene chloride to take out a sample for characterization. A number average molecular weight of 3400 was determined from the ${ }^{1} \mathrm{H}$ NMR spectrum. In order to double the molecular weight a similar, second amount of ethylene oxide was transferred into the reaction bottle for subsequent polymerization. After complete conversion a molecular weight of $7100 \mathrm{~g} / \mathrm{mol}$ was found. Preliminary experiments indicated that poly(ethylene oxide)-block-poly( $\varepsilon$-caprolactone) diblock copolymers could be prepared by the addition of $\varepsilon$-caprolactone monomer to a reaction mixture of freshly polymerized ethylene oxide, after cooling the reaction mixture and dissolving it in dichloromethane. 
1) S. Boileau, "Comprehensive Polymer Science", vol. 3, Eastmond G. C., Ed., Pergamon Press, Oxford 1989, p. 467

2) R. A. Miller, C. C. Price, J. Polym. Sci. 34, 161 (1959)

3) H. Haubenstock, V. Panchalingam, G. Odian, Makromol. Chem. 188, 2789 (1987)

4) T. Aida, S. Inoue, Macromolecules 14, 1162 (1981)

5) Y. Watanabe, T. Aida, S. Inoue, Macromolecules 23, 2612 (1990)

6) M. Yamashita, Y. Takemoto, E. Ihara, H. Yasuda, Macromolecules 29, 1798 (1996)

7) W. M. Stevels, M. J. K. Ankoné, P. J. Dijkstra, J. Feijen, Macromolecules 29, 3332 (1996)

8) W. M. Stevels, M. J. K. Ankoné, P. J. Dijkstra, J. Feijen, Macromol. Chem. Phys. 196, 3687 (1995)

9) S. Kinugasa, A Takatsu, H. Nakanishi, H. Nakahara, S. Hattori, Macromolecules 25, $4849(1992)$

10) J. M. Dust, Z. Fang, J. M. Harris, Macromolecules 23, 3742 (1990) 